\title{
Reducing Hospital Use and Expenditures through Utilization Review
}

\section{Findings from an Outcome Evaluation}

\author{
Thomas M. Wickizer, Ph.D.,†* Paul J. Feldstein, Ph.D.,市 John R. C. Wheeler, \\ Ph.D.,§ and Margaret C. McDonald, B.S. $\dagger$
}

$\dagger$ Department of Health Services, University of Washington, Seattle, Washington 98195; $¥$ Graduate School of Management, University of California, Irvine, California 92717; and §Department of Health Services Management and Policy, The University of Michigan, Ann Arbor, Michigan 48109.

\begin{abstract}
Utilization review (UR) has become a prominent approach to cost containment now used by almost $65 \%$ of private group insurance plans. Although insurers have increasingly relied on UR to contain health care costs, until recently little was known about the effects of this cost containment approach. This article reviews some of the key findings of a UR evaluation, based on analysis of claims data on 223 insured groups for the years 1984 through 1986. The evaluation found that $U R$ reduced admissions by $12 \%$, inpatient expenditures by $8 \%$, and total expenditures by $6 \%$. It was estimated that UR generated net savings of $\$ 115$ per employee per year. Groups adopting UR with high baseline rates of hospital use had larger expenditure reductions and greater net savings. It appears that UR can play an important role in private cost containment and help improve medical care resource consumption.
\end{abstract}

In 1987, private health insurance payments totaled almost $\$ 158$ billion, representing 32 cents of each health care dollar spent. As a result of accelerating insurance premiums, employers, in their role as payers of health care, have sought to develop approaches for containing health care costs and have turned to prospective utilization review (UR). UR, which seeks to ensure that hospital care used is appropriate and necessary, has expanded rapidly in recent years $(1,2)$, and $65 \%$ of private group insurance plans now use some form of UR (3). Research showing that as much as $20 \%$ of hospital admissions and $35 \%$ of inpatient days are inappropriate or unnecessary (4-8) has led advocates to claim that UR can reduce costs $(9,10)$ and, at the same time, improve the quality of care.

However, until very recently little was actually

\footnotetext{
* To whom requests for reprints should be addressed at the Department of Health Services, SC-37, University of Washington, Seattle, WA 98195
}

known about the impact of UR on hospital use or costs. In reviewing the literature, Wickizer (11) has discussed the wide range of findings produced by UR evaluations. Early evaluations of the Professional Standards Review Organization (PSRO) program found that UR had limited effect on reducing hospital days among Medicare patients (12-14), with no net cost savings $(15,16)$. On the other hand, evaluations of PSRO prototype programs and other public UR programs produced findings suggesting that UR could reduce hospital inpatient rates by $10-15 \%$, with attendant cost savings (17-20). However, the reliability of the findings produced by these evaluations has been questioned on methodological grounds $(11,21)$. More recent assessments of private UR programs have produced some encouraging findings suggesting that UR can generate impressive cost savings (22-25). But these assessments also suffer from methodological problems that make their findings largely unreliable (11).

For the past several years, the authors (T. M. W., P. J. F., and J. R. W.) have been involved in an ongoing project, initiated at The University of Michigan, to evaluate the effects of UR on hospital use and expenditures. Findings of this evaluation have been reported in the academic and scientific literature (26, 27 ) but not in the professional literature. Physicians, nurses, and administrators involved in the planning or operation of UR programs represent a key group of health care professionals who need current evaluative information on UR. The purpose of this article is to review the major findings of our evaluation.

\section{THE UR PROGRAM}

The UR program analyzed was established in 1983 by CNA Insurance Companies of Chicago and made 
available to policyholders as a benefit plan option. The UR program consists of two related review activities: pre-admission authorization and concurrent review. Pre-admission authorization is usualy conducted by an off-site review panel staffed by registered nurses and physician advisors but may in some cases be conducted by on-site medical personnel.

The second review activity, concurrent review, provides a review of the patient's treatment plan, along with the planned length of stay. Concurrent review is done on-site by a registered nurse, who reviews the treatment plan to ensure that it meets established medical criteria. UR is compulsory for all employees and dependents. Employers adopting UR pay a premium surcharge of approximately $\$ 1.40$ to $\$ 1.80 \mathrm{per}$ month per employee depending upon the type of review selected and the number of employees covered.

Like many private UR programs, the UR program analyzed relies on financial incentives to alter patient behavior. Patients failing to comply with UR procedures are subject to financial penalties (physicians and hospitals are not subject to penalties). For example, if employees do not get authorization for admission as required by pre-admission review, they may have their covered inpatient expenses reduced by some percentage (often $50 \%$ ) or by a set dollar amount before normal benefits are applied. Thus, the UR program seeks to encourage the appropriate use of hospital services through economic incentives, in effect raising the relative price of care determined by UR to be inappropriate. Assuming patients are responsive to these higher prices, one would expect UR to reduce the use of inpatient care.

\section{THE EVALUATION DESIGN}

Our evaluation sought to answer a series of questions regarding $U R$, including:

1. What is the effect of UR on hospital use and expenditures?

2. Does UR have any effect on the rate of growth in expenditures?

3. Does the effect of UR vary across diagnoses?

4. Do groups with high baseline levels of utilization achieve greater expenditure savings as a result of UR?

5. Do health care market factors influence the effectiveness of UR?

6. Does UR produce net cost savings for employers?

The unit of analysis for the research was the insured group. A group may represent an entire insured pop- ulation covered under an employer's health insurance policy or it may represent some subset of the employees and dependents covered under that policy. For example, a large company with multiple plants in different geographic areas may structure its insurance policy so that each site constitutes an insured group whose claims are processed separately and whose premiums are set independently.

Groups were selected for study based on several criteria, including size of insured population, availability of claims data, type of coverage provided, and number of quarters of account activity. 223 groups were selected for study meeting these criteria. Of these groups, 91 operated under UR during 1984 through 1986, and the remainder did not have any cost containment program in effect during this time. Although not randomly sampled, the groups selected for study are well distributed in terms of geographic region and industry and very representative of the under-65 general population in terms of hospital use. Eighteen percent of the groups are located in the northeast, $35 \%$ in the north central region, $26 \%$ in the south, and $21 \%$ in the west. The average group includes approximately 1500 insureds, comprising 660 employees and 840 dependents.

Quarterly claims data for 1984 through 1986 on the 223 groups were pooled, making 1844 observations available for analysis. The claims data provided information on hospital utilization and medical care expenditures, which formed the outcome measures for the evaluation. The measures analyzed included: (1) admissions per 1000 insured persons; (2) length of stay (LOS); (3) hospital routine (room and board) expenditures per insured person; (4) hospital ancillary expenditures per insured person; and (5) total expenditures per insured person (consisting of all inpatient and outpatient expenditures). All variables were measured on a per quarter basis; expenditures were adjusted through the Medical Care Price Index to reflect January 1985 prices.

To control for factors believed likely to influence hospital use, we collected information on employee demographic characteristics, health care market area factors, and benefit plan features. This information was obtained from the insurance carrier's account files and from various secondary sources, including the American Medical and American Hospital Association annual surveys, Interstudy Health Maintenance Organization (HMO) surveys, and the Area Resource File data tape. Descriptive information on the dependent and independent variables used in the analysis is provided in Table 1.

To evaluate the effects of UR, we compared the utilization and expenditures of groups that operated 
Table 1

\section{Summary of Key Variables Used in Evaluating UR ${ }^{a}$}

\begin{tabular}{|c|c|}
\hline Measure & $\begin{array}{c}\text { Mean } \\
\text { (Standard Deviation) }\end{array}$ \\
\hline Outcome measures & \\
\hline Admissions per 1000 insured persons & $\begin{array}{c}26.27 \\
(13.47)\end{array}$ \\
\hline Average length of stay & $\begin{array}{c}6.23 \\
(3.79)\end{array}$ \\
\hline $\begin{array}{l}\text { Hospital room and board expenditures per } \\
\text { insured person }\end{array}$ & $\begin{array}{r}\$ 41.84^{b} \\
(\$ 36.22)\end{array}$ \\
\hline $\begin{array}{l}\text { Hospital ancillary expenditures per insured } \\
\text { person }\end{array}$ & $\begin{array}{c}\$ 58.81 \\
(\$ 52.24)\end{array}$ \\
\hline Hospital expenditures per admission & $\begin{array}{l}\$ 3,923.50 \\
(\$ 2,566.10)\end{array}$ \\
\hline $\begin{array}{l}\text { Total medical expenditures per insured per- } \\
\text { son }\end{array}$ & $\begin{array}{c}\$ 216.89 \\
(\$ 117.24)\end{array}$ \\
\hline Independent variables & \\
\hline Percent male employees under 30 & $\begin{array}{l}11.1 \\
(6.0)\end{array}$ \\
\hline Percent female employees under 30 & $\begin{array}{l}9.1 \\
(6.9)\end{array}$ \\
\hline Percent male employees $30-50$ & $\begin{array}{l}36.5 \\
(9.5)\end{array}$ \\
\hline Percent female employees $30-50$ & $\begin{array}{l}17.7 \\
(8.3)\end{array}$ \\
\hline Percent male employees over 50 & $\begin{array}{l}18.6 \\
(9.9)\end{array}$ \\
\hline Percent female employees over 50 & $\begin{array}{l}6.7 \\
(3.6)\end{array}$ \\
\hline $\begin{array}{l}\text { Expenditures on childbirth and pregnancy } \\
\text { as a percent of total expenditures }\end{array}$ & $\begin{array}{l}7.8 \\
(7.7)\end{array}$ \\
\hline $\begin{array}{l}\text { Expenditures on heart disease as a percent } \\
\text { of total expenditures }\end{array}$ & $\begin{array}{r}3.9 \\
(7.3)\end{array}$ \\
\hline $\begin{array}{l}\text { Medicare coordination of benefit savings as } \\
\text { a percent of total expenditures }\end{array}$ & $\begin{array}{c}1.2 \\
(4.2)\end{array}$ \\
\hline HMO penetration rate & $\begin{array}{c}11.9 \\
(12.9)\end{array}$ \\
\hline Practicing physicians per 1000 population & $\begin{array}{c}2.1 \\
(0.8)\end{array}$ \\
\hline Percent of general practice physicians & $\begin{array}{l}13.0 \\
(10.1)\end{array}$ \\
\hline Hospital occupancy & $\begin{array}{l}66.7 \\
(8.9)\end{array}$ \\
\hline Deductible level & $\begin{array}{l}\$ 130.26 \\
(\$ 52.65)\end{array}$ \\
\hline Coinsurance rate ${ }^{\circ}$ & $\begin{array}{l}80.0 \\
(3.8)\end{array}$ \\
\hline Mental health inpatient coinsurance rate ${ }^{c}$ & $\begin{array}{l}81.7 \\
(20.1)\end{array}$ \\
\hline $\begin{array}{l}\text { Percent expenditures covered for semipri- } \\
\text { vate hospital room }\end{array}$ & $\begin{array}{l}88.7 \\
(26.7)\end{array}$ \\
\hline $\begin{array}{l}\text { Percent expenditures covered for office } \\
\text { visits }\end{array}$ & $\begin{array}{l}86.3 \\
(17.7)\end{array}$ \\
\hline $\begin{array}{l}\text { Percent expenditures covered for hospital } \\
\text { outpatient services }\end{array}$ & $\begin{array}{l}89.8 \\
(20.6)\end{array}$ \\
\hline Utilization review ( $1=$ UR, 0 otherwise) & $\begin{array}{c}0.41 \\
(0.49)\end{array}$ \\
\hline
\end{tabular}

under UR with those that did not, using multivariate analysis to control for the effects of external factors. A more detailed discussion of the statistical model and analytic procedures used is presented elsewhere (27).

\section{FINDINGS}

The evaluation showed that UR reduced hospital use and expenditures, even after controlling for a large number of external factors. A summary of the key findings is presented in Table 2. As shown, UR reduced admissions by approximately $12 \%$ but had no effect on LOS, indicating the effectiveness of preadmission authorization but not concurrent review. Our inability to control for changes in case mix could explain the failure to find an effect on LOS. If preauthorization review keeps patients who are less ill out of the hospital, a group's case mix is likely to change. Failure to control for this change would then result in a biased estimate of UR's effect on LOS.

UR reduced hospital routine and ancillary expenditures by approximately $8 \%$, mainly by lowering admissions through pre-admission authorization. We also examined whether UR reduced inpatient expenditures per admission to assess whether it affected the resource consumption of patients once they were admitted. This would occur through the review procedures used to perform concurrent review. It was found that UR did not have any significant effect on expenditures per admission. However, as with LOS, our inability to control for case mix may have confounded the analysis and led to this finding. If patients less seriously ill are kept out of the hospital through preadmission authorization, it is possible those admitted may be sicker and require more ancillary services.

Total medical expenditures, the last measure shown, represents the key outcome measure analyzed by the evaluation. Because it captures all inpatient and outpatient expenditures, total expenditures provides a comprehensive measure of medical resource consumption. As shown, UR reduced total expenditures by approximately $6 \%$. Translated into a dollar figure, this implies a reduction in expenditures of approximately

\section{Table 2}

\section{Summary of the Effects of UR on Hospital Use and Expenditures ${ }^{2}$}

\begin{tabular}{lc}
\hline \multicolumn{1}{c}{ Measure } & $\begin{array}{c}\text { Percent Change } \\
\text { Due to UR }\end{array}$ \\
\hline Hospital admissions & $-12 \% \pm 4 \%$ \\
Length of stay & $-8 \% \pm 5 \%$ \\
Hospital inpatient routine expenditures & $-9 \% \pm 6 \%$ \\
Hospital inpatient ancillary expenditures & - \\
Hospital inpatient expenditures per admission & $-6 \% \pm 3 \%$ \\
Total medical expenditures & \\
\hline$N=1844$. & \\
Note: All measures were statistically significant ( $p<0.05)$, except length of \\
stay and inpatient expenditures per admission. The figures on the right corre- \\
spond roughly to 95\% confidence intervals.
\end{tabular}


$\$ 56$ per insured person per year based on annualized expenditures.

Observers have speculated that UR may lead to large increases in the use of outpatient care through a substitution effect. To date, no meaningful analysis has been performed to address this issue because evaluators have not had the requisite data. The total medical expenditure estimate shown in Table 2, however, indicates that the substitution effect is not large enough to overwhelm the estimated reduction in inpatient expenditures. (The effect of UR on total medical expenditures is a weighted average of its effects on inpatient and outpatient expenditures.) Recent analysis performed by Wickizer, Wheeler, and Feldstein (28) to evaluate UR's effect on outpatient expenditures indicated that UR did lead to a large percentage increase in hospital outpatient department expenditures. However, this increase was not of quantitative importance because hospital outpatient department expenditures represent only a small portion (less than 10\%) of total expenditures.

In addition to examining UR's average effects, we sought to explore whether its effects varied across diagnoses. To evalute this, we constructed a set of expenditure measures representing mental health, medical, and surgical services. We found that UR had the greatest impact on expenditures for the surgical area (29). This may imply that UR protocols are better developed for or more easily applied to surgical cases than to other cases.

One of the questions we explored through the evaluation was whether UR had any effect on the growth in expenditures over time. Our expectation was that UR would not affect expenditure growth but would rather lead to a one-time decrease in the level of expenditures. The findings of analyses we performed on several expenditure measures supported this expectation and showed that UR did have little effect on expenditure growth.

Another question we explored was whether the effectiveness of UR varied according to groups' baseline level of utilization. Our analysis suggested it did. Groups adopting UR with baseline admission levels above 120 admissions per 1000 insureds per year achieved reductions in hospital use and expenditures roughly two to three times greater than average. This may indicate a proportionately greater use of unnecessary or inappropriate care among these groups.

A related question we have recently examined is whether UR is more likely to be effective in reducing use and expenditures under certain market conditions than under others. Since UR is intended to reduce unnecessary or inappropriate care, one would expect UR to be more effective in market areas where there is a higher likelihood of observing unnecessary care, other factors being equal (30). Initial exploratory analysis has shown that the effects of UR do vary across market conditions. For example, UR was significantly more effective in reducing hospital days and inpatient expenditures for groups located in areas with high surgical rates as compared to groups located in areas with low rates $(-29.2$ versus -8.5 days per 1000 insureds per quarter, $P<.01 ;-\$ 15.30$ versus $-\$ 8.15$ per insured per quarter, $P<.10$ ) (Market areas were divided into high and low areas according to the median value of the stratifying variable, e.g., surgical rate, HMO penetration rate, overall area admission rate, etc.). It was also more effective in reducing hospital days and inpatient expenditures for groups located in areas with high admission rates and for groups located in areas with low HMO penetration rates. More detailed analyses recently conducted confirmed that market characteristics can have an important influence on the effectiveness of UR programs (31).

Finally, we examined whether UR generates net savings for employers. Reductions in total medical expenditures do not represent net savings, because there is a premium surcharge for UR that employers have to pay. We estimated UR's net savings for a prototypical 1000-employee firm by extrapolating on the basis of total expenditure reductions after accounting for the cost of UR. This analysis indicated that UR yielded annual net savings of approximately $\$ 115$ per employee, based on $6 \%$ reduction in total medical expenditures (27). Of course, some groups, such as those with high baseline levels of admissions or those located in markets with high surgical rates, are likely to achieve larger savings from UR.

One of the major concerns in conducting evaluations like the one described here is the problem of selection. Since we did not use experimental procedures, we could not be sure that the UR and non-UR groups analyzed differed only with respect to exposure to UR. They may have also have differed on unmeasured factors, and these differences could introduce bias into the analysis. To determine whether our findings might have been influenced by selection effects, we performed several selectivity bias tests. The results of these tests were consistent and showed no evidence of a selection effect (27). Therefore, we believe the findings of our evaluation provide reliable estimates of UR's true effects.

\section{CONCLUSION}

UR appears to be an effective approach to cost containment. Our evaluation found that UR reduced 
admissions by $12 \%$, inpatient routine expenditures by $8 \%$, inpatient ancillary expenditures by $9 \%$, and total medical expenditures by $6 \%$. Analysis suggests that UR may be most effective in reducing expenditures for surgical cases. It was estimated that UR led to net savings of approximately $\$ 115$ per year per insured person. Expenditure reductions occurred as a result of reducing admissions through pre-admission authorization. UR had little effect on LOS or inpatient expenditures per admission; however, these findings could be confounded by case-mix effects. The effectiveness of UR was influenced by groups' baseline level of utilization as well as by external market conditions operating in the larger environment that may be predictive of unnecessary care.

Our evaluation has several limitations that should be kept in mind. First, the evaluation examined only one insurance carrier's UR program. Other programs using different review procedures or different incentives may lead to different outcomes. Hence, caution should be used in generalizing the findings presented here. Second, our evaluation did not examine whether UR actually reduced unnecessary or inappropriate care. Rather, it examined reductions in aggregate use and expenditures. Future research should conduct more detailed analyses to address this question.

Third, this evaluation did not examine the many indirect effects of UR, the most important of which is the effect of UR on the quality of care and patient health status. While it is often assumed that prospective UR leads to improved quality and better outcomes, this is an empirical question that has not yet been analyzed. The effects of UR on physician and hospital administration time, the physician-patient relationship, and physician clinical autonomy represent other areas that should be explored by future research.

One recent study undertaken by the Institute of Medicine (IOM) did address some of these areas, as well as other issues regarding private UR $(32,33)$. The concern of the IOM committee investigating private UR was over how utilization review is conducted, how burdensome this review is for patients and providers, how standards for appropriate care are established, and how equitable appeals processes are. The committee's report noted that some states, concerned about possible abuses of UR, had already regulated UR activity. However, it concluded that federal regulation of private UR activities was premature and unwarranted. One of the favorable aspects of UR recognized by the IOM Committee was its potential to stimulate the development of useful clinical standards and to foster dialogue between providers and payers of care.
The field of UR has seen dramatic growth over the past several years. What is needed now are careful systematic evaluations to determine how UR can best be used as a tool to promote cost containment and to improve the quality of care. Physicians, nurses, administrators, and others involved in the operation of UR programs are in a key position to initiate or support evaluative research. Only through such research will the information needed to improve the performance of UR become available.

\section{ACKNOWLEDGMENTS}

The research described in this article was supported by Grant 9894 from The Robert Wood Johnson Foundation. Partial support was also provided by Grant HS05991 (to T. M. W.) from the Agency for Health Care Policy and Research (formerly the National Center for Health Services Research and Office of Technology Assessment).

\section{References}

1. Ermann D. Hospital utilization review: past experience, future directions. J Health Polit Policy Law 1988;13(4):683-704.

2. Gabel J, Jajich-Toth C, deLissovoy G, et al. The changing world of group health insurance. Health Aff 1988;7(3):48-65.

3. Gabel J, DiCarlo S, Fink S, et al. Employer-sponsored health insurance in America. Health Aff 1989;8:116-128.

4. Gertman PM, Restuccia JD. The appropriateness evaluation protocol: a technique for assessing unnecessary days of hospital care. Med Care 1981;19(6):855-871.

5. Restuccia JD, Gertman PM, Dayno JJ, et al. A comparative analysis of appropriateness of hospital care. Health Aff 1984;3(2):130-138.

6. Restuccia JD, Kemper BE, Payne S. et al. Factors affecting appropriateness of hospital care in Massachusetts. Health Care Fin Rev 1986;8(1):47-54.

7. Siu AL, Sonnenberg FA, Manning WG, et al. Inappropriate use of hospitals in a randomized trial of health insurance plans. $N$ Engl J Med 1986;315:1259-1266.

8. Strumwasser I, Paranjpe NV, Hall H. Determining hospital stays. Business and Health 1987;(February):18-21.

9. Donahue R. Unnecessary health care wastes $\$ 100$ billion. $M e d-$ ical Benefits 1987;4(6):38-42.

10. DiBlase D. Effective review can trim health expenses. Business Insurance 1986;20(41):35-38.

11. Wickizer, TM. The effects of utilization review on hospital use and expenditures: a review of the literature and an update on recent findings. Med Care Rev 1990;47(3), in press.

12. Dobson A, Greer JG, Carlson RH, Davis FA, et al. PSROs: their current states and their impact to date. Inquiry. 1978;15:113128.

13. Health Care Financing Administration. Professional Standards Review Organization 1978 Program Evaluation. Department of Health Education and Welfare, 1979;(January, Washington D.C.).

14. Health Care Financing Administration. Professional Standards Review Organization 1979 Program Evaluation. Department of Health Education and Welfare, 1980;(April, Washington D.C.).

15. Congressional Budget Office. The effects of PSROs on health 
care costs: current findings and future evaluations, 1979;(June, U.S. Government Printing Office, Washington, D.C.).

16. Congressional Budget Office. The impact of PSROs on health care costs: update of CBO's 1979 evaluation, 1981;(January, U.S. Government Printing Office, Washington, D.C.).

17. Flashner BA, Reed S, Colurn RW, Fine, PR. Professional standards review organization. JAMA 1973;223(13):1473-1484.

18. Brian E. Foundation for medical care control of hospital utilization: CHAP-a PSRO prototype. $N$ Engl $J$ Med 1973;288(17):878-882.

19. Brian EW. Government control of hospital utilization: a California experience. $N$ Engl $J$ Med 1972;286(25):1340-1344.

20. Westphal M, Frazier E, Miller M. Changes in average length of stay and average charges generated following institution of PSRO review. Health Serv Res 1979;14(4):253-265.

21. Sayetta RB. Critique of an earlier study of the Sacremento Medical Care Foundation's certified hospital admission program (CHAP). Med Care 1976;14(1):81-90.

22. Ness CO. Utilization review, in conjunction with redesign, saves employer 27\% over projected 1984 costs. Employee Benefit Plan Review 1985;(March/April):104-108.

23. O'Donnell PS. Managing health costs under a fee-for-service plan. Business and Health 1987;(March):38-41.

24. Richards G. Business spurs UR growth. Hospitals 1984;(March):96-100

25. Shahoda T. Preadmission review cuts hospital use. Hospitals 1984;(August):54-56
26. Feldstein PJ, Wickizer TM, Wheeler JR. Private cost containment: the effects of utilization review programs on health care use and expenditures. New Engl J Med 1988;318:1310-1315.

27. Wickizer TM, Wheeler JR, Feldstein PJ. Does utilization review reduce unnecessary care and contain costs? Med Care $1989 ; 27(6): 632-646$.

28. Wickizer TM, Wheeler JR, Feldstein PJ. Have hospital cost containment programs contributed to the rise in outpatient expenditures? An analysis of the substitution effect associated with utilization review. 1990 (submitted for publication).

29. Wickizer TM. The effect of hospital utiliization review on medical expenditures in selected diagnostic areas. 1990 (submitted for publication).

30. Brook RH, Williams KN, Rolph JE. Controlling the use and cost of medical services: The New Mexico Experimental Medical Care Review Organization - a four year case study. Med Care 1983;16(9):1-83.

31. Wheeler JR, Wickizer TM. The relationship of health care market characteristics to the effectiveness of utilization review programs. Inquiry 1990; Fall, in press.

32. Institute of Medicine. Controlling costs and changing patient care? The role of utilization management. Institute of Medicine Committee on Utilization Management by Third Parties. Washington, D.C., National Academy Press, 1989.

33. Field MJ, Gray BH. Should we regulate 'utilization management'? Health Aff 1989;8(4): 103-113. 